\title{
Green space, social inequalities and neonatal mortality in France
}

\author{
Wahida Kihal-Talantikite ${ }^{1 *}$, Cindy M Padilla ${ }^{1,2}$, Benoît Lalloué ${ }^{1,2,3}$, Marcello Gelormini', Denis Zmirou-Navier ${ }^{1,2,3}$ \\ and Severine Deguen ${ }^{1,2}$
}

\begin{abstract}
Background: Few studies have considered using environmental amenities to explain social health inequalities. Nevertheless, Green spaces that promote good health may have an effect on socioeconomic health inequalities. In developed countries, there is considerable evidence that green spaces have a beneficial effect on the health of urban populations and recent studies suggest they can have a positive effect on pregnancy outcomes. To investigate the relationship between green spaces and the spatial distribution of infant mortality taking account neighborhood deprivation levels.
\end{abstract}

Methods: The study took place in Lyon metropolitan area, France. All infant deaths that occurred between 2000 and 2009 were geocoded at census block level. Each census block was assigned greenness and socioeconomic deprivation levels. The spatial-scan statistic was used to identify high risk cluster of infant mortality according to these neighborhood characteristics.

Results: The spatial distribution of infant mortality was not random with a high risk cluster in the south east of the Lyon metropolitan area $(p<0.003)$. This cluster disappeared $(p=0.12)$ after adjustment for greenness level and socioeconomic deprivation, suggesting that these factors explain part of the spatial distribution of infant mortality. These results are discussed using a conceptual framework with 3 hypothetical pathways by which green spaces may have a beneficial effect on adverse pregnancy outcomes: (i) a psychological pathway, (ii) a physiological disruption process and (iii) an environmental pathway.

Conclusions: These results add some evidence to the hypothesis that there is a relationship between access to green spaces and pregnancy outcomes but further research is required to confirm this.

Keywords: Greenness level, Neighborhood deprivation, Infant mortality, Spatial analysis

\section{Background}

In developed countries, the leading causes of neonatal morbidity and mortality are adverse pregnancy outcomes such as preterm birth [1], congenital malformations [2], low birth weight [1] and intrauterine growth retardation [3]. Socio-epidemiological research documented a social gradient of infant mortality and stillbirth $[4,5]$. Infant mortality and its risk factors are more common among women of low socioeconomic status [6,7]. A wide literature describes various deprivation measures related to adverse birth outcome, including composite indices $[6,8]$ and proxy variables of socioeconomic characteristics, such

\footnotetext{
* Correspondence: wahida.kihal@ehesp.fr

${ }^{1}$ EHESP School of Public Health-Rennes, Sorbonne-Paris Cité, France

Full list of author information is available at the end of the article
}

as income [9], level of education [10,11], unemployment [10], occupation [10], percentage of persons below the poverty level [10], homeownership [12] and percentage of immigrants [9]. However, only a few studies have combined individual and the neighborhood socioeconomic status $[7,13,14]$.

Environmental factors have recently been proposed as determinants which could partially explain social health inequalities. Most of these studies focused on environmental nuisances, such as ambient air pollution related to traffic or industry [15-17] and noise [18,19]. Only a few have considered environmental benefits [20]. However, several recent papers have shown that access to green spaces may have a beneficial effect on health $[21,22]$ and may relate to urban socioeconomic inequalities [20].

\section{Biomed Central}

(c) 2013 Kihal-Talantikite et al.; licensee BioMed Central Ltd. This is an open access article distributed under the terms of the Creative Commons Attribution License (http://creativecommons.org/licenses/by/2.0), which permits unrestricted use, distribution, and reproduction in any medium, provided the original work is properly cited. 
Two recent reviews have reported that green space, defined as "open, undeveloped land with natural vegetation, parks or forest", have beneficial health effect on morbidity [23] and mortality [20]. The literature suggests various ways in which green space may promote health by encouraging physical activity [24,25] and walking [26], reducing pollution (air pollution $[27,28]$ and noise [29]) and increasing social contact [30]. In addition, a wide literature explored the psychological benefits of green space. By relieving stress [31], green spaces have a positive influence on people's self-perceived health [32], emotional and mental health [33] and well-being [26]. Some studies have shown that, in addition to promoting psychological health, physical or visual contact with green space can have a physiologically restorative effect. Many health benefits have been reported, such as a reduced incidence of cardio-vascular diseases [34], overweight and obesity [35] and even mortality [20].

To our knowledge, only two teams, one in Spain and one in Portland investigated, the effects of green spaces on adverse pregnancy outcomes [36-39]. An association was reported between living near a green space and birth weight or gestational age. These recent findings highlight the need for research into the relationship between green space and pregnancy outcomes in order to improve our understanding of the underlying mechanisms.

Different socioeconomic groups still have unequal access to green spaces. The Spanish study showed a clear association between living close to a green space and birth weight or gestational age, although only for the group with the lowest level of education [36]. Other authors also reported that people with greater access to green space were less likely to be deprived than those with limited access $[40,41]$. Green spaces that promote good health may therefore have an effect on socioeconomic health inequalities.

In this context, our study explored the relationship between living close to green spaces and spatial distribution of infant mortality in Lyon metropolitan area, France, between January 2000 and December 2009, and assessed the effect of socioeconomic level on this relationship. We conducted a spatial-scan statistic analysis, which is used for an increasing number of spatial epidemiology applications [42]. The results of this analysis were then discussed using a theoretical model elaborated to explain the possible mechanisms by which green space and socioeconomic level may be related to adverse pregnancy outcomes.

\section{Methods}

\section{Study setting}

The study was carried out in Lyon metropolitan area, an urban area covering $515.96 \mathrm{~km}^{2}$ with a population of 1,340,155 in 2009 located in east-central France. The prevalence of infant death over the study period (2000-2009) was on average of 3.5 per 1000 live birth (Max: 4.1\%o birth in 2001, Min: $3.1 \%$ o birth in 2004) [43].

\section{Health data}

The dependant variable is infant mortality, defined as all cases of deaths of infants less than 1 year old. The data was collected from all city halls of each municipality by those involved in the "Equit'Area" project (www. equitarea.org). Each case was geocoded on the basis of the parents' postal address using CAZU software produced by INSEE (National Institute for Statistics and Economic Studies) which assigns street names and numbers to census blocks (2000 inhabitants on average). The exhaustiveness of the death data is $96,5 \%$, by comparing the total number of cases collected from the death and birth registries of the study area City Halls with the cases obtained from the National Epidemiological Center for Medical Causes of Death (CepiDc-Inserm). Due to the mortality statistical system in France, whose smallest spatial resolution scale is the city, no data exists at a census block level, a limitation that forced us to visit the death registries in all municipalities to retrieve the information. It was possible to check that the cases were evenly distributed across the deprivation and greenness scales. Overall, 715 cases of infant deaths in Lyon metropolitan area were collected between January 2000 and December 2009. The CNIL (French National Commission for Digitalized Information and Liberty) gave its permission to retrieve geocode and analyze the health data.

\section{Neighborhood characteristics \\ Socioeconomic index}

Socioeconomic and demographic data (income, level of education, employment, immigration, etc.) were obtained from the 2006 census conducted by INSEE at census block level.

In order to characterize the neighbourhood deprivation level, we used a deprivation index. This measure combines material and social aspects of deprivation to measure the overall socioeconomic status. It includes variables related to education, income, occupation, unemployment, and immigration (see Table 1) to cover and capture the different dimensions of the deprivation.

Successive principal-component analyses were used to create the deprivation index based on Lalloue et al. [44]. The measure of neighborhood deprivation was categorized into three groups according to the tertiles of the index distribution (Table 1): low, moderate and high deprivation (Table 1).

\section{Green space index}

Spatial land cover datasets for Lyon Metropolitan area were sought and processed using ArcMap GIS software (ESRI) to produce a green space index. The definition of 
Table 1 Description of the deprivation categories

\begin{tabular}{lll}
\hline Data & Characteristics & Description \\
\hline $\begin{array}{l}\text { Classes of } \\
\text { deprivation }\end{array}$ & $\begin{array}{l}\text { Group 1: low } \\
\text { deprivation }\end{array}$ & $\begin{array}{l}\text { Census block with high median income, } \\
\text { low proportion of households without a } \\
\text { car, low proportion with non-owner- } \\
\text { occupied primary residences }\end{array}$ \\
& $\begin{array}{l}\text { Group 2: } \\
\text { moderate } \\
\text { deprivation }\end{array}$ & $\begin{array}{l}\text { Census block with median income } \\
\text { average, medium proportion of } \\
\text { households without a car, medium } \\
\text { proportion with non-owner-occupied } \\
\text { primary residences }\end{array}$ \\
& $\begin{array}{l}\text { Group 3: high } \\
\text { deprivation }\end{array}$ & $\begin{array}{l}\text { Cencome, high proportion of } \\
\text { incouseholds without a car, high } \\
\text { houportion with non-owner-occupied } \\
\end{array}$ \\
& primary residences
\end{tabular}

green space included natural area (e.g. parks, forest) as these are generally treated as green space in the literature.

Our greenness index represented proportion of the geographical area $\left(\mathrm{km}^{2}\right)$ of green space in the total area of census block.

This index, measured in each census block, was categorized into three groups defined according to the tertiles of the index distribution: low, moderate and high greenness.

\section{Statistical analysis}

\section{Spatial methodology}

The spatial scan statistics implemented in SaTScan software [45] were used to carry out a cluster analysis to determine the spatial aggregation of infant mortality.
This approach showed the presence of high risk clusters of infant mortality named "most likely clusters" and their spatial location. The number of cases in each census block was assumed to follow a Poisson distribution.

The method used by SaTScan imposes a circular scanning window of variable radius (from zero up to $50 \%$ of the population size [46]). This circular window was placed at each centroid of the census block and moved across the whole study area to compare the infant mortality rate in the windows with the rate expected under a random distribution. The identification of the most likely clusters was based on a likelihood ratio test [47] with an associated p-value obtained using Monte Carlo replications [48]. The on-line appendix describes the analytical strategy in detail (Additional file 1).

\section{Results}

Figure 1A shows the spatial distribution of the socioeconomic deprivation index. The most wealthy census blocks are located in the center and peripheral parts of the study area, while the most deprived blocks are in the centraleastern and southern areas of the metropolitan area.

Figure 1B shows the spatial distribution of the greenness index, the census blocks with the highest greenness levels being concentrated in the peripheral and western parts of the Lyon metropolitan area and the census blocks with the lowest greenness levels being in the central-eastern and southern parts of the Lyon metropolitan area. The spatial variations of the deprivation and greenness index have similar patterns.

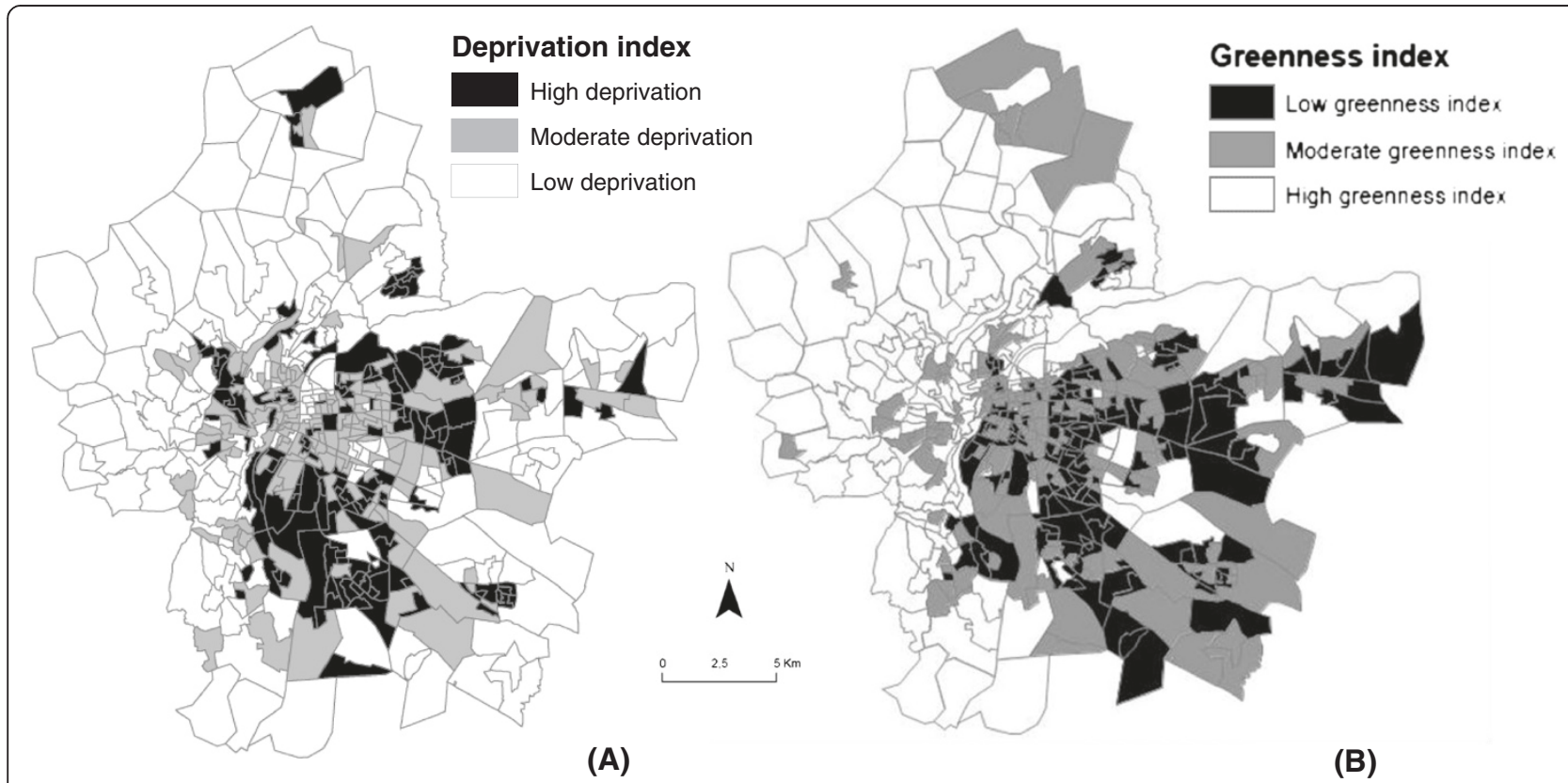

Figure 1 Spatial distribution of the neighborhood socioeconomic index (A); spatial distribution of greenness levels modeled across the Lyon metropolitan area (B). 


\section{Spatial analysis}

\section{Identify high risk clusters of infant mortality}

Figure 2A shows the location of the most likely cluster in the south-east of Lyon metropolitan area, with an infant mortality rate 1.70 times higher than in the rest of the study area $(\mathrm{p}=0.003)$. This cluster is composed of 53 census blocks with a population of around 19,401 (Table 2, unadjusted analysis).

\section{Adjusted scan statistical analysis} Greenness level and spatial distribution of infant mortality After adjusting for greenness index, the most likely cluster was in the same position (Figure 2A), with a log likelihood ratio reduced from 12 to 10.06 (Table 2, adjusted analysis -stage 2). This indicated that the greenness level only partially explained the excess infant mortality risk found in the south-eastern part of Lyon metropolitan area [46]. However, the cluster was still significant after adjustment $(R R=1.52 ; p=0.01)$, indicating that the excess infant mortality risk should be explained by other variables.

\section{Neighborhood deprivation level and spatial distribution of infant mortality}

Adjusting for deprivation index increased the size of the most likely cluster to 66 census blocks located in the same general location (Figure 2B), with a population of about 21,907 in a radius of $9258.9 \mathrm{~m}$ (Table 2, adjusted analysis stage 2). The risk of infant mortality was 1.54 higher than in the rest of the metropolitan area, the log likelihood ratio reduced from 12 to 8.74 and the cluster of infant mortality became borderline significant $(\mathrm{p}=0.06$ ), indicating that the socioeconomic index explained a major part of the excess infant mortality shown by the unadjusted analysis [46].

\section{Greenness level, neighborhood deprivation level and spatial} distribution of infant mortality

After adjustment for greenness and deprivation levels and their interaction, in stage 3 of the analysis (Table 2, adjusted analysis - stage 3), the most likely cluster became not significant $(p=0.12)$ but remained in the same general location (Figure 2A). When interaction between deprivation and greenness levels was included, there was no difference in the results, meaning that both factors had an independent effect.

\section{Discussion}

To our knowledge, this is the first study of the spatial relationship between greenness, deprivation level and infant mortality. Our results revealed that infant mortality rates were not randomly distributed over the study area with a cluster of excess infant mortality in the south-western area of Lyon metropolitan area. After adjusting for greenness and neighborhood deprivation level, high risk cluster of infant mortality disappeared, suggesting that these factors explained the excess infant mortality.

Our findings are consistent with recent studies investigating adverse pregnancy outcomes conducted at the individual level. Two studies highlighted a reduction in the risk of small for gestational age [39] and low birth weight [36-38] associated with a greater surrounding tree canopy

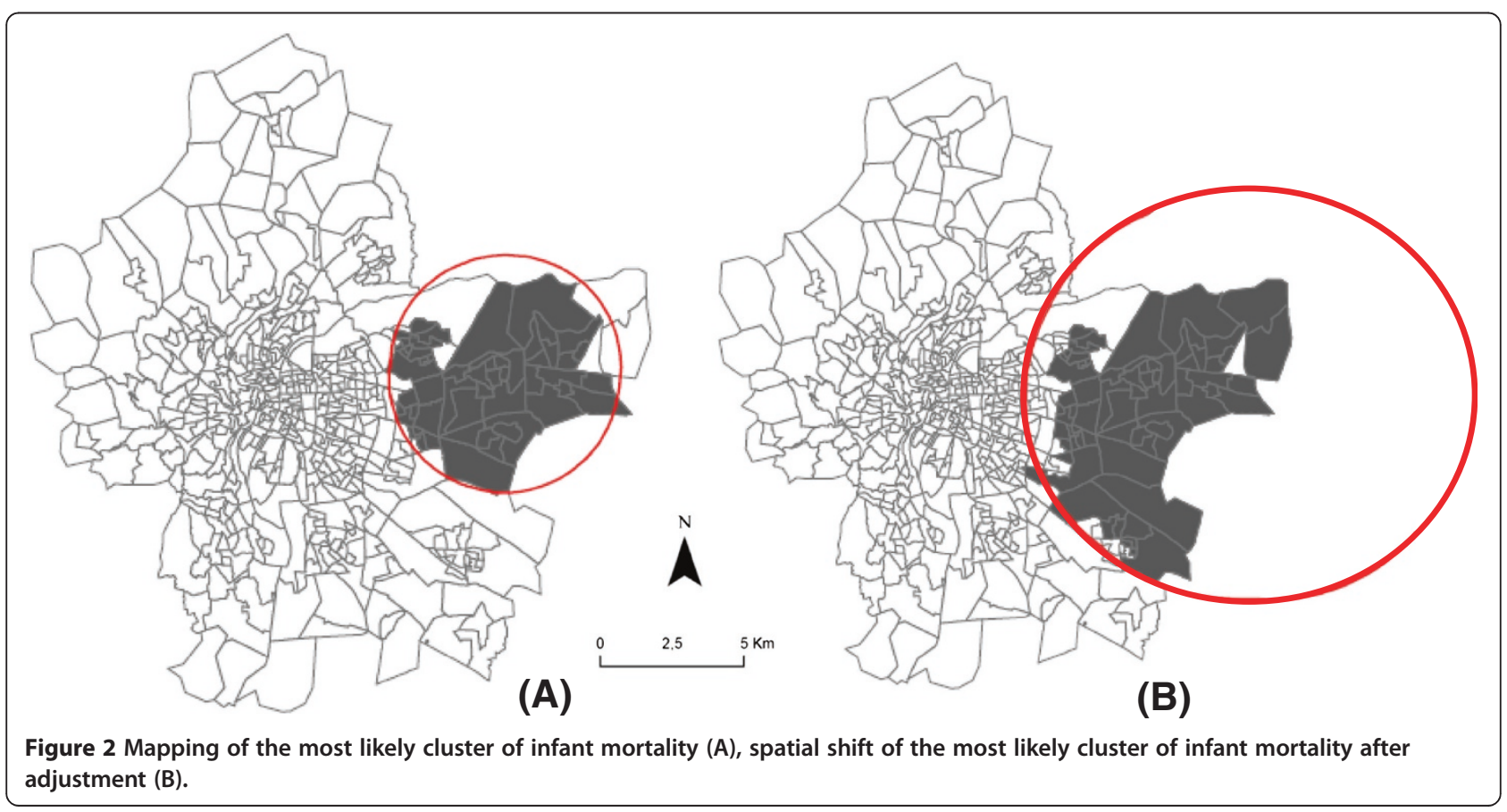


Table 2 The most likely clusters resulting from the unadjusted analysis (stage 1) and adjusted analysis (stages 2 and 3 )

\begin{tabular}{|c|c|c|c|c|c|c|c|c|}
\hline Most likely cluster & Confounders & Radius (meter) & Census block included & Expected cases & Observed cases & $\mathbf{R R}^{\mathrm{a}}$ & LLr $^{b}$ & $\mathrm{p}$-value \\
\hline \multicolumn{9}{|c|}{ Unadjusted analysis ${ }^{\mathrm{c}}$ - Stage 1- } \\
\hline & None & 5117.81 & 53 & 73.30 & 116 & 1.70 & 12.00 & 0.003 \\
\hline \multicolumn{9}{|c|}{ Adjusted analysis ${ }^{\text {d }}$-Stage 2- } \\
\hline & Green space & 5117.81 & 53 & 76.46 & 116 & 1.52 & 10.06 & 0.01 \\
\hline & SES level & 9258.9 & 66 & 85.68 & 124 & 1.54 & 8.74 & 0.06 \\
\hline \multicolumn{9}{|c|}{ Adjusted analysis ${ }^{\mathrm{e}}$ - Stage 3- } \\
\hline SES level and greenn & ess level & 9258.9 & 66 & 85.95 & 124 & 1.50 & 7.60 & 0.12 \\
\hline
\end{tabular}

${ }^{\mathrm{a} R R}$ : Relative Risks.

bLr: Log Likelihood ratio.

'Unadjusted analysis, to identify and localize the most likely cluster/s of high risk of mortality, (first step of analysis).

${ }^{d}$ Adjusted analysis for greenness level or socio-economic neighbourhood (deprivation index), (second step of analysis).

${ }^{\mathbf{e}}$ Adjusted analysis for greenness level and deprivation index at the neighbourhood level including the interaction between the two variables, (third step of analysis).

[39] or greenness [36-38]. However, no association was observed with gestational age [37-39]. A recent paper reported that living close to green space had various maternal benefits including a decrease in musculoskeletal discomfort, reduced incidence of muscle cramps and lower limb edema [49]. However, the exact mechanisms of these beneficial effects were not established.
The present study provided some additional empirical support for the potential role of access to green space in reducing the risk of adverse pregnancy outcomes.

A conceptual model of the mediating variables associated with green space and of their hypothetical relationship with pregnancy outcomes is proposed below (Figure 3).

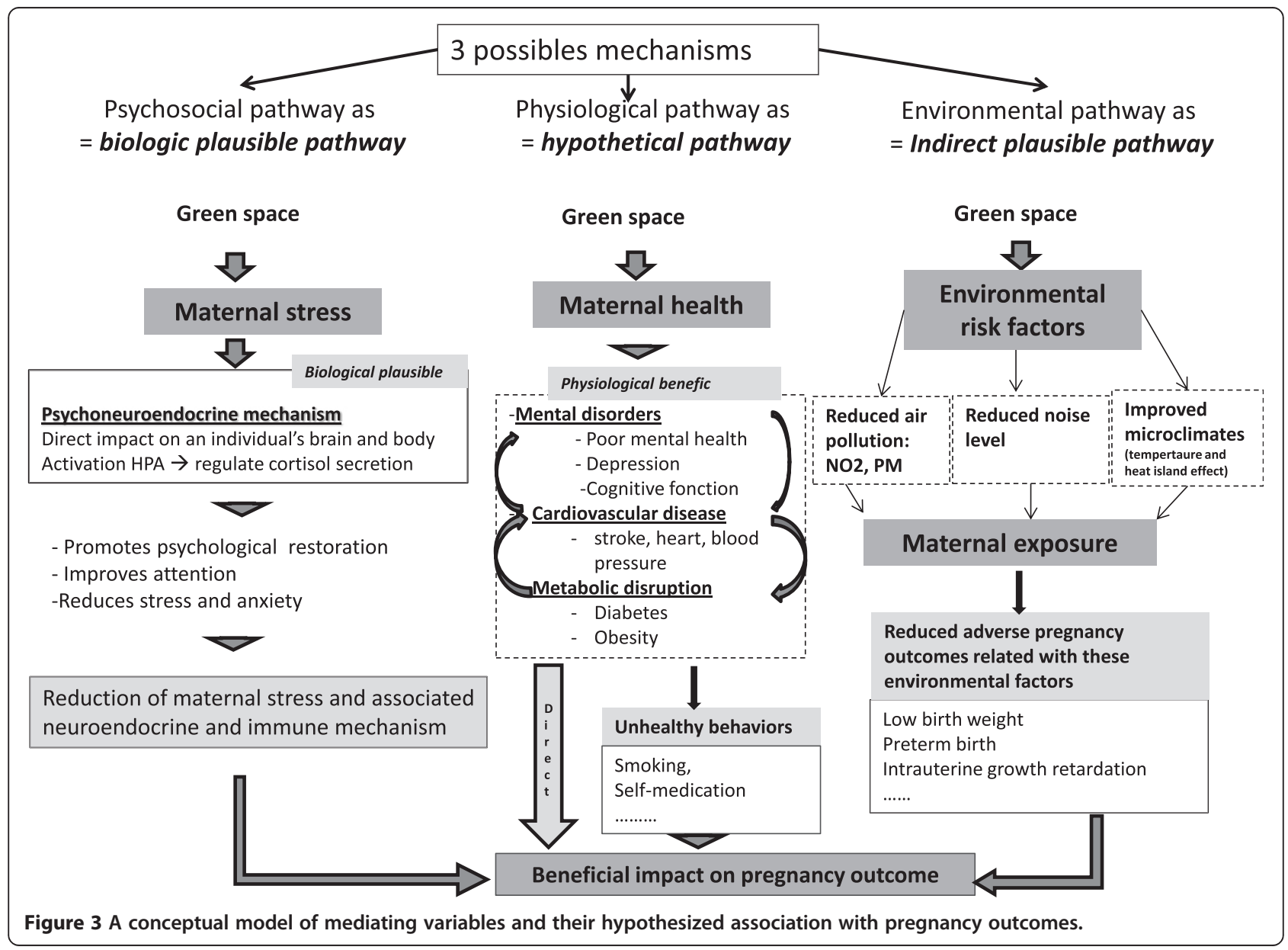


We propose hereafter 3 hypothetical pathways through which green spaces may have a beneficial effect on pregnancy outcomes.

\section{Psychological pathway as a possible biological pathway} The main mechanism by which green space may be associated with a favorable pregnancy outcome is stress reduction. A large number of experimental studies have produced strong evidence of the positive effect of nature on recovery from stress and attention fatigue [22,31]. Contact with natural environments promotes psychological restoration [50] and reduces stress and anxiety [51-53]. Green space has a positive effect on stressful life events including mood and stress levels not only by providing people with a pleasant view but also by encouraging physical activity $[54,55]$ and social contact $[30,56]$.

There is evidence that perception of green space has a direct impact on a person's brain and body through psycho-neuroendocrine mechanisms, including the functioning of the hypothalamic pituitary adrenal axis which regulates cortisol secretion and whose deregulation is associated with a range of adverse pregnancy outcomes.

The main theoretical model for these responses, known as Ulrich's psychoevolutionary model [52,53], has been confirmed by several experimental studies that revealed that being in or viewing green space was linked to a reduction in physiological manifestations of stress, including heart rate, blood pressure, skin conductance and muscle tension [53,57]. Surprisingly, these findings were not reported in other papers [58].

Some beneficial effects of green space may operate through reduction of maternal stress and the neuroendocrine and immune mechanisms which may alter fetomaternal exchanges $[59,60]$, causing limited fetal nutrition and/or oxygenation, leading to a reduction in fetal growth $[61,62]$ and preterm birth [63].

\section{Physiological disruption as a hypothetical pathway}

The second pathway posits that green space may promote maternal health by encouraging physical activity and facilitating social contact. There may be a number of underlying mechanisms. Firstly, by providing the opportunity for physical activity, access to green spaces may improve maternal cardiovascular activity $[49,64]$ which, by a number of biological pathways, may reduce blood pressure, decrease the concentrations of proinflammatory cytokines and leptin in the peripheral circulation, reduce oxidative stress and improve plasma lipids and lipoprotein concentrations [64]. A large number of studies have produced strong evidence of these positive effects including reduction in the risk of hypertensive disorders $[25,65]$ and the risk of preeclampsia $[64,66]$, both conditions that are associated with preterm birth [67], low birth weight [68] and infant mortality $[69,70]$.
Secondly, by encouraging physical activity, green space may have positive effects on metabolic disorders including weight gain [25] and diabetes [71] during pregnancy. The weight gain during pregnancy has significant health implications on the newborn [72]. Maternal obesity and a sedentary lifestyle during pregnancy have been associated with preterm birth [25,73] and increased risk of congenital anomalies, a leading cause of stillbirth and infant mortality, and important contributors to preterm birth and early childhood morbidity [72].

A recent meta-analysis and epidemiological studies documented that women who are physically active during pregnancy have a $24 \%$ lower odds of developing gestational diabetes than inactive women [71] and that the risk of spontaneous preterm birth increased with increasing levels of pregnancy [74].

Thirdly, through an association between physical activity $[75,76]$ and social contact $[33,77]$ on the one hand and mental health on the other, including well-being, mood and depression/insomnia during pregnancy, green space may reduce mental disorders and their effects on adverse outcomes [25,78,79].

\section{Environmental pathways, as an indirect pathway}

The third hypothetical pathway is the effect of green space on the living environment of pregnant women. Recent studies reported that green space had beneficial effects on environmental factors such as (i) ambient air pollution, (ii) noise levels and (iii) temperature which may lead to adverse pregnancy outcomes.

Green space is associated with lower personal exposure to particulate matter $\left(\mathrm{PM}_{2.5}\right)$ [37]. Broad leaved woodland reduces ambient air pollution and tree-lined streets have around a quarter of the particle concentrations of streets without trees [80,81]. Other studies showed that urban trees, particularly low VOCs emitting species, can reduce urban ozone levels [82-84]. In 2000, Nowak [85] described four main processes by which vegetation may affect air quality: (i) temperature reduction and other microclimatic effects, (ii) removal of air pollutants, (iii) emission of volatile organic compounds and tree maintenance emissions, (iv) energy effects on buildings. Vegetation may play a variety of roles as a physical filter for harmful gases and particulate matter [80,81]. By reducing air temperature, radiation and absorption, tree transpiration and tree canopies can improve air quality because the emissions of many pollutants, including ozone-forming chemicals, are temperature dependent. Trees also improve air quality by reducing energy use and pollutant emissions from power plants $[85,86]$. Such mechanisms which reduce maternal exposure to hazardous air pollutants may be the means by which living close to green space may have positive effects on pregnancy outcomes [87]. 
Exposure to noise during pregnancy has been associated with a higher risk of preterm birth $[88,89]$ and low birth weight $[90,91]$. Green space may reduce environmental noise and so promote a better psychosocial maternal environment that reduces the risk of adverse pregnancy outcomes. Although there is little research establishing the actual benefits of urban green space as a distance barrier to environmental noise, recent papers suggest that green space, particularly trees and large shrubs, is able to mitigate noise in urban areas by providing a barrier to screen out noise [92,93]. "Noise buffers" composed of trees and shrubs may reduce noise by up to $15 \mathrm{db}$ [81]. It is also suggested that trees in urban areas may absorb some traffic noise [29]. In addition, perceived intrusion of noise from traffic can be reduced by vegetation obscuring the noise source and associated traffic movement [81]. In 2007, GidlöfGunnarsson and Öhrström proposed a brief conceptual model for the role of green space on noise annoyance, behaviors and perception of the residential soundscape related to road traffic noise [94].

Our hypothesis highlights the complexity of the mechanisms which link green space to pregnancy outcomes and suggests that other factors such as the socioeconomic status of pregnant women [20,31] may interact to promote or reduce the beneficial effects of green space. Several studies describe disparities in the degree of access to green space according to individual or neighborhood socioeconomic status. In general, deprived neighborhoods in urban areas have fewer parks and walking trails and poorer access to green space in comparison with non-deprived areas $[40,41,95,96]$. Proximity to and usage of green space depend on the level of education or on income [97]. People living in deprived neighborhoods are less likely to make use of green spaces because they do not perceive the need to do so $[98,99]$, although this has been challenged by other authors.

The ecological nature of our study design did not allow us to assess the usage of green space by people in Lyon area population. Another limitation of our study was the construction of the greenness index. The information on topography or land cover used to construct the index did not distinguish between different types of vegetation, which may affect the pathways proposed for the effects of noise or ambient air pollution. Unlike the Normalized Difference Vegetation Index (NDVI) which measures small-scale green spaces in a standardized way, and other more specific synthetic measures of greenness, our index only measured the degree of greenness in each census block.

Finally, because the outcome of interest is rare, the statistical power of this study is limited. Despite these limitations, the results are consistent with those based on the more detailed NDVI index [38].

\section{Conclusion}

These results add evidence to the relationship between access to green space and pregnancy outcomes. Policies that ensure an equitable distribution of green spaces within urban areas may help to promote fair access to healthy environments. Further studies should be carried out on the effect of access to green spaces on pregnancy outcomes to document the mechanisms involved.

\section{Additional file}

Additional file 1: Analytical strategy and results interpretation.

\section{Abbreviations}

RR: Relative risks; LLr: Log likelihood ratio; PM 2.5: Particulate matter < $2.5 \mu \mathrm{m}$.

\section{Competing interests}

The authors declare they have no competing financial interests.

\section{Authors' contributions}

WK undertook the spatial analysis, produced the map and conceptual model, drafted the paper and carried out the literature review. CP collected health data, geocoded the cases to the IRIS level, contributed to interpret the results and draft and finalize the paper. BL implemented the statistical model and helped to finalize the paper. MG carried out the literature review and helped to draft and finalize the paper. DZ-N, Head of the Environmental and Occupational Health Department at the EHESP and co-principal investigator of the Equit'Area Project, was responsible for quality assurance and rigor in the data analysis, reviewed the drafts of the article and contributed to finalize it. SD, principal investigator of the Equit'Area project studying the role of environmental exposure on health inequalities, monitored the general work, helped with the analysis and interpretation of the results and contributed to draft and finalize the paper. All authors read and approved the final manuscript.

\section{Acknowledgments}

This project is funded by the ANR (French National Research Agency), contract-2010-PRSP-002-01). This work was supported by the ADEME (French Environment and Energy Management Agency) by a PhD grant for Cindy Padilla

The authors would like to thank Grégoire Rey researcher at INSERM, CépiDc, Le Kremlin-Bicêtre, France for his contribution.

\section{Author details}

${ }^{1}$ EHESP School of Public Health-Rennes, Sorbonne-Paris Cité, France. ${ }^{2}$ INSERM U1085-IRSET - Research Institute of Environmental and Occupational Health, Rennes, France. ${ }^{3}$ Lorraine University Medical SchoolVandoeuvre-les-Nancy-France, Vandoeuvre-Les-Nancy, France.

Received: 27 March 2013 Accepted: 7 October 2013

Published: 20 October 2013

\section{References}

1. Mathews TJ, MacDorman MF: Infant Mortality Statistics From the 2008 Period Linked Birth/Infant Death Data Set. Nat Vital Stat Rep 2010, 60:5.

2. Kurinczuk JJ, Hollowell J, Boyd PA, Oakley L, Brocklehurst P, Gray R: Inequalities in infant mortality project briefing paper 4 . The contribution of congenital anomalies to infant mortality. Oxford: National Perinatal Epidemiology Unit; 2010.

3. Kramer MS: Intrauterine growth and gestational duration determinants. Pediatrics 1987, 80:502-511.

4. Borrell C, Cirera E, Ricart M, Pasarín Ml, Salvador J: Social inequalities in perinatal mortality in a Southern European city. Eur J Epidemiol 2003, 18:5-13.

5. Singh GK, Kogan MD: Persistent socioeconomic disparities in infant, neonatal, and postneonatal mortality rates in the United States, 1969-2001. Pediatrics 2007, 119:e928-e939. 
6. Calling S, Li X, Sundquist J, Sundquist K: Socioeconomic inequalities and infant mortality of 46,470 preterm infants born in Sweden between 1992 and 2006. Paediatr Perinat Epidemiol 2011, 25:357-365.

7. Janevic T, Stein CR, Savitz DA, Kaufman JS, Mason SM, Herring AH: Neighborhood deprivation and adverse birth outcomes among diverse ethnic groups. Ann Epidemiol 2010, 20:445-451.

8. O'Campo P, Burke JG, Culhane J, Elo IT, Eyster J, Holzman C, Messer LC, Kaufman JS, Laraia BA: Neighborhood deprivation and preterm birth among non-Hispanic Black and White women in eight geographic areas in the United States. Am J Epidemiol 2008, 167:155-163.

9. Auger N, Giraud J, Daniel M: The joint influence of area income, income inequality, and immigrant density on adverse birth outcomes: a population-based study. BMC Public Health 2009, 9:237.

10. Pickett KE, Ahern JE, Selvin S, Abrams B: Neighborhood socioeconomic status, maternal race and preterm delivery: a case-control study. Ann Epidemiol 2002, 12:410-418.

11. Luo Z-C, Wilkins R, Kramer MS: Effect of neighbourhood income and maternal education on birth outcomes: a population-based study. CMA 2006, 174:1415-1420.

12. Roberts EM: Neighborhood social environments and the distribution of low birthweight in Chicago. Am J Public Health 1997, 87(4):597-603.

13. Agyemang C, Vrijkotte TGM, Droomers M, Van der Wal MF, Bonsel GJ, Stronks K: The effect of neighbourhood income and deprivation on pregnancy outcomes in Amsterdam, The Netherlands. J Epidemiol Community Health 2009, 63:755-760.

14. Kaufman JS, Dole N, Savitz DA, Herring AH: Modeling community-level effects on preterm birth. Ann Epidemiol 2003, 13:377-384.

15. Carbajal-Arroyo L, Miranda-Soberanis V, Medina-Ramón M, Rojas-Bracho L, Tzintzun G, Solís-Gutiérrez P, Méndez-Ramírez I, Hurtado-Díaz M, Schwartz J, Romieu I: Effect of PM(10) and O(3) on infant mortality among residents in the Mexico City Metropolitan Area: a case-crossover analysis, 1997-2005. J Epidemiol Community Health 2011, 65:715-721.

16. Genereux M, Auger N, Goneau M, Daniel M: Neighbourhood socioeconomic status, maternal education and adverse birth outcomes among mothers living near highways. J Epidemiol Community Health 2008, 62:695-700.

17. Woodruff TJ, Parker JD, Kyle AD, Schoendorf KC: Disparities in exposure to air pollution during pregnancy. Environ Health Perspect 2003 111:942-946.

18. Passchier-Vermeer W, Passchier WF: Noise exposure and public health; 2000:123-131.

19. Guidelines for Community Noise. Geneva: WHO; 1999. Available at: http:// www.who.int/docstore/peh/noise/guidelines2.html.

20. Mitchell R, Popham F: Effect of exposure to natural environment on health inequalities: an observational population study. Lancet 2008, 372:1655-1660.

21. Lee ACK, Maheswaran R: The health benefits of urban green spaces: a review of the evidence. J Public Health (Oxf) 2011, 33:212-222.

22. Bowler DE, Buyung-Ali LM, Knight TM, Pullin AS: A systematic review of evidence for the added benefits to health of exposure to natural environments. BMC Public Health 2010, 10:456.

23. Maas J, Verheij RA, Vriesde S, Spreeuwenberg P, Schellevis FG, Groenewegen PP: Morbidity is related to a green living environment. J Epidemiol Community Health 2009, 63:967-973.

24. Bedimo-Rung AL, Mowen AJ, Cohen DA: The significance of parks to physical activity and public health: a conceptual model. Am J Prev Med 2005, 28:159-168.

25. Vinikoor-Imler LC, Messer LC, Evenson KR, Laraia BA: Neighborhood conditions are associated with maternal health behaviors and pregnancy outcomes. Soc Sci Med 2011, 73:1302-1311.

26. Pretty J, Griffin M, Sellens M, Pretty C: Green exercise: complementary roles of nature, exercise and diet in physical and emotional well-being and implications for public health policy. Colchester: University of Essex, CES Occasional paper; 2003.

27. Nowak DJ, Crane DE, Stevens JC: Air pollution removal by urban trees and shrubs in the United States. Urban Forestry and Urban Greening 2006, 4:115-123.

28. Paoletti E, Bardelli T, Giovannini G, Pecchioli L: Air quality impact of an urban park over time. Procedia Environmental Sciences 2011, 4:10-16.

29. Greater London Authority: Health Issues in Planning: Best Practice Guidance. London: Greater London Authority; 2007.
30. Maas J, Van Dillen SME, Verheij RA, Groenewegen PP: Social contacts as a possible mechanism behind the relation between green space and health. Health Place 2009, 15:586-595

31. Ward Thompson C, Roe J, Aspinall P, Mitchell R, Clow A, Miller D: More green space is linked to less stress in deprived communities: Evidence from salivary cortisol patterns. Landscape and Urban Planning 2012, 105:221-229.

32. Maas J, Verheij RA, Groenewegen PP, de Vries S, Spreeuwenberg P: Green space, urbanity, and health: how strong is the relation? J Epidemiol Community Health 2006, 60:587-592.

33. Sugiyama T, Leslie E, Giles-Corti B, Owen N: Associations of neighbourhood greenness with physical and mental health: do walking social coherence and local social interaction explain the relationships? J Epidemiol Community Health 2008, 62:e9.

34. Hu Z, Liebens J, Rao KR: Linking stroke mortality with air pollution, income, and greenness in northwest Florida: an ecological geographical study. Int J Health Geogr 2008, 7:20.

35. Lachowycz K, Jones AP: Greenspace and obesity: a systematic review of the evidence. Obes Rev 2011, 12:e183-e189.

36. Dadvand P, De Nazelle A, Figueras F, Basagaña X, Su J, Amoly E, Jerrett M, Vrijheid M, Sunyer J, Nieuwenhuijsen MJ: Green space, health inequality and pregnancy. Environ Int 2012, 40:110-115.

37. Dadvand P, De Nazelle A, Triguero-Mas M, Schembari A, Cirach M, Amoly E, Figueras F, Basagaña X, Ostro B, Nieuwenhuijsen M: Surrounding greenness and exposure to air pollution during pregnancy: an analysis of personal monitoring data. Environ Health Perspect 2012, 120:1286-1290

38. Dadvand P, Sunyer J, Basagaña X, Ballester F, Lertxundi A, FernándezSomoano A, Estarlich M, García-Esteban R, Mendez MA, Nieuwenhuijsen MJ: Surrounding greenness and pregnancy outcomes in four spanish birth cohorts. Environ Health Perspect 2012, 120:1481-1487.

39. Donovan GH, Michael YL, Butry DT, Sullivan AD, Chase JM: Urban trees and the risk of poor birth outcomes. Health Place 2011, 17:390-393.

40. Crawford D, Timperio A, Giles-Corti B, Ball K, Hume C, Roberts R, Andrianopoulos N, Salmon J: Do features of public open spaces vary according to neighbourhood socio-economic status? Health Place 2008, 14:889-893.

41. Koohsari M: Access to public open space: is distribution equitable across different socio-economic areas. Journal of Urban and Environmental Engineering 2011, 5:67.

42. Bambhroliya AB, Burau KD, Sexton K: Spatial analysis of county-level breast cancer mortality in Texas, Volume 2012; 2012:959343.

43. Institute for Research and Information in Health Economics; Available at: http://www.irdes.fr/EcoSante/RegionsEtDepartements.htm

44. Lalloué B, Monnez JM, Padilla C, Kihal W, Le Meur N, Zmirou-Navier D, Deguen S: A statistical procedure to create a neighborhood socioeconomic index for health inequalities analysis. International Journal for Equity in Health 2013, 12:21.

45. Information Management Services, Inc: SaTScan: software for the spatial, temporal, and space-time scan statistics, version 6.0. 2005.

46. Kulldorff M, Feuer EJ, Miller BA, Freedma LS: Breast Cancer Clusters in the Northeast United States: A Geographic Analysis. Am J Epidemio/ 1997, 146:161-170.

47. Kulldorff M: A spatial scan statistic. Communications in Statistics - Theory and Methods 1997, 26:1481-1496.

48. Dwass M: Modified Randomization Tests for Nonparametric Hypotheses Ann. Math. Statist. 1957, 28:181-187.

49. Melzer K, Schutz Y, Boulvain M, Kayser B: Physical activity and pregnancy: cardiovascular adaptations, recommendations and pregnancy outcomes. Sports Med 2010, 40:493-507.

50. Kaplan R, Kaplan S: The Experience of Nature: A Psychological Perspective Cambridge: Cambridge University Press; 1989.

51. Hartig T, Evans GW, Jamner LD, Davis DS, Gärling T: Tracking restoration in natural and urban field settings. Journal of environmental psychology 2003, 23:109-123.

52. Ulrich RS: Aesthetic and affective response to natural environment. Human Behavior \& Environment: Advances in Theory \& Research 1983, 6:85-125.

53. Ulrich $R$, Simons $R$, Losito B, Fiorito E, Miles M, Zelson M: Stress recovery during exposure to natural and urban environments. Journal of Environmental Psychology 1991, 11:201-230. 
54. Barton J, Pretty J: What is the best dose of nature and green exercise for improving mental health? A multi-study analysis. Environ Sci Technol 2010, 44:3947-3955

55. Roe J, Aspinall P: The restorative benefits of walking in urban and rural settings in adults with good and poor mental health. Health Place 2011, 17:103-113.

56. Heinrichs M, Baumgartner T, Kirschbaum C, Ehlert U: Social support and oxytocin interact to suppress cortisol and subjective responses to psychosocial stress. Biol Psychiatry 2003, 54:1389-1398.

57. Hartig T, Mang M, Evans GW: Restorative effects of natural environment experiences. Environment and Behavior 1991, 23:3-26.

58. Ottosson J, Grahn P: A comparison of leisure time spent in a garden with leisure time spent indoors: on measures of restoration in residents in geriatric care. Landscape Research 2005, 30:23-55.

59. Morishima $\mathrm{HO}$, Yeh MN, James LS: Reduced uterine blood flow and fetal hypoxemia with acute maternal stress: experimental observation in the pregnant baboon. Am J Obstet Gynecol 1979, 134:270-275.

60. Schell LM, Gallo MV, Denham M, Ravenscroft J: Effects of pollution on human growth and development: an introduction. J Physiol Anthropol 2006, 25:103-112.

61. Myers RE: Maternal psychological stress and fetal asphyxia: a study in the monkey. Am J Obstet Gynecol 1975, 122:47-59.

62. Myers RE: Production of fetal asphyxia by maternal psychological stress. Pavlov J Biol Sci 1977, 12:51-62.

63. Hobel CJ: Stress and preterm birth. Clin Obstet Gynecol 2004, 47:856-880. discussion 881-882.

64. Pivarnik J, Chambliss H, Clapp J, Dugan S, Hatch M, Lovelady C, Mottola M, Williams M: Impact of physical activity during pregnancy and postpartum on chronic disease risk. Med Sci Sports Exerc 2006, 38:989-1006.

65. Yeo S, Steele NM, Chang MC, Leclaire SM, Ronis DL, Hayashi R: Effect of exercise on blood pressure in pregnant women with a high risk of gestational hypertensive disorders. J Reprod Med 2000, 45:293-298.

66. Sorensen TK, Williams MA, Lee I-M, Dashow EE, Thompson ML, Luthy DA: Recreational physical activity during pregnancy and risk of preeclampsia. Hypertension 2003, 41:1273-1280.

67. Xiong X, Mayes D, Demianczuk N, Olson DM, Davidge ST, Newburn-Cook C, Saunders LD: Impact of pregnancy-induced hypertension on fetal growth. Am J Obstet Gynecol 1999, 180:207-213.

68. Xiong X, Demianczuk NN, Buekens P, Saunders LD: Association of preeclampsia with high birth weight for age. Am J Obstet Gynecol 2000 , 183:148-155.

69. Sibai B, Dekker G, Kupferminc M: Pre-eclampsia. The Lancet 2005, 365:785-799.

70. Roberts JM, Redman CW: Pre-eclampsia: more than pregnancy-induced hypertension. Lancet 1993, 341:1447-1451.

71. Tobias DK, Zhang C, Van Dam RM, Bowers K, Hu FB: Physical activity before and during pregnancy and risk of gestational diabetes mellitus: a meta-analysis. Diabetes Care 2011, 34:223-229.

72. Stothard KJ, Tennant PWG, Bell R, Rankin J: Maternal overweight and obesity and the risk of congenital anomalies: a systematic review and meta-analysis. JAMA 2009, 301:636-650.

73. Evenson KR, Siega-Riz AM, Savitz DA, Leiferman JA, Thorp JM Jr: Vigorous leisure activity and pregnancy outcome. Epidemiology 2002, 13:653-659.

74. Hedderson MM, Ferrara A, Sacks DA: Gestational diabetes mellitus and lesser degrees of pregnancy hyperglycemia: association with increased risk of spontaneous preterm birth. Obstet Gynecol 2003, 102:850-856.

75. DaCosta D, Rippen N, Dritsa M, Ring A: Self-reported leisure-time physical activity during pregnancy and relationship to psychological well-being. J Psychosom Obstet Gynaecol 2003, 24:111-119.

76. Poudevigne MS, O'Connor PJ: Physical activity and mood during pregnancy. Med Sci Sports Exerc 2005, 37:1374-1380.

77. Seguin L, Potvin L, St-Denis M, Loiselle J: Chronic stressors, social support, and depression during pregnancy. Obstetrics \& Gynecology 1995, 85:583-589.

78. Faisal-Cury A, Araya R, Zugaib M, Menezes PR: Common mental disorders during pregnancy and adverse obstetric outcomes. J Psychosom Obstet Gynaecol 2010, 31:229-235.

79. Pien GW, Schwab RJ: Sleep disorders during pregnancy. Sleep 2004, 27:1405-1417.

80. Lavin T, Higgins C, Metcalfe O, Jordan A: Health Effects of the Built Environment: A Review. The Institute of Public Health in Ireland 2006,

81. LUC (Land and Use Consultants): Making the Links: Greenspace and Quality of Life; 2004:91
82. Cardelino CA, Chameides W: Natural hydrocarbons, urbanization, and urban ozone. J Geophys Res 1990, 95(D9):13,971-13,979.

83. Taha $\mathrm{H}$ : Modeling impacts of increased urban vegetation on ozone air quality in the South Coast Air Basin. Atmos Environ 1996, 20:3423-3430.

84. Nowak D: The interactions between urban forests and global climate change. In Global climate change and the urban forest: GCRCC and Franklin Press. Appeaning, A; 2000:31-44.

85. Nowark D: The effects of urban trees on air quality. Syracuse, NY: USDA Forest Service; 2002.

86. Akbari $\mathrm{H}$ : Shade trees reduce building energy use and $\mathrm{CO} 2$ emissions from power plants. Environ Pollut 2002, 116(Suppl 1):S119-S126.

87. Sram RJ, Binková B, Dejmek J, Bobak M: Ambient air pollution and pregnancy outcomes: a review of the literature. Environ Health Perspect 2005, 113:375-382

88. Hartikainen-Sorri AL, Sorri M, Anttonen HP, Tuimala R, Läärä E: Occupational noise exposure during pregnancy: a case control study. Int Arch Occup Environ Health 1988, 60:279-283.

89. Mamelle N, Laumon B, Lazar P: Prematurity and occupational activity during pregnancy. Am J Epidemiol 1984, 119:309-322.

90. Hartikainen AL, Sorri M, Anttonen H, Tuimala R, Läärä E: Effect of occupational noise on the course and outcome of pregnancy. Scand J Work Environ Health 1994, 20:444-450

91. Knipschild P, Meijer H, Sallé H: Aircraft noise and birth weight. Int Arch Occup Environ Health 1981, 48:131-136.

92. Greenspace Scotland: Health Impact Assessment of Greenspace: A guide; 2008.

93. RCEP: The Urban Environment, Royal Commission on Environmental Pollution. London: The Stationery Office; 2007.

94. Gidlöf-Gunnarsson A, Öhrström E: Noise and well-being in urban residential environments: The potential role of perceived availability to nearby green areas. Landscape and Urban Planning 2007, 83:115-126.

95. Richardson E, Pearce J, Mitchell R, Day P, Kingham S: The association between green space and cause-specific mortality in urban New Zealand: an ecological analysis of green space utility. BMC Public Health 2010, 10:240.

96. Estabrooks PA, Lee RE, Gyurcsik NC: Resources for physical activity participation: does availability and accessibility differ by neighborhood socioeconomic status? Ann Behav Med 2003, 25:100-104.

97. Talen E: The social equity of urban service distribution: an exploration of park access in Pueblo, Colorado and Macon, Georgia. Urban Geog 1997, 18:521-541.

98. Timperio A, Ball K, Salmon J, Roberts R, Crawford D: Is availability of public open space equitable across areas? Health Place 2007, 13:335-340.

99. Jones A, Hillsdon M, Coombes E: Greenspace access, use, and physical activity: understanding the effects of area deprivation. Prev Med 2009 49:500-505.

doi:10.1186/1471-2393-13-191

Cite this article as: Kihal-Talantikite et al:: Green space, social inequalities and neonatal mortality in France. BMC Pregnancy and Childbirth 2013 13:191.

\section{Submit your next manuscript to BioMed Central and take full advantage of:}

- Convenient online submission

- Thorough peer review

- No space constraints or color figure charges

- Immediate publication on acceptance

- Inclusion in PubMed, CAS, Scopus and Google Scholar

- Research which is freely available for redistribution 